\title{
Impact of VKORC1, CYP4F2 and NQO1 gene variants on warfarin dose requirement in Han Chinese patients with catheter ablation for atrial fibrillation
}

\author{
Jiao $\mathrm{Li}^{1 \dagger}$, Wenlong Yang ${ }^{2+}$, Zhonghui $\mathrm{Xie}^{2+}$, Kun Yu${ }^{3 \dagger}$, Yuhua Chen ${ }^{4+}$ and Kaijun Cui ${ }^{2^{*}}$ (1)
}

\begin{abstract}
Background: The anticoagulation of atrial fibrillation catheter ablation during the perioperative stage does matter and should be treated with discretion. We aimed to assess impact of three important genes participating in vitamin K cycle (i.e. VKORC1 rs9923231, CYP4F2 rs2108622 and NQO1 rs1800566) on the daily stable warfarin dose requirement in Sichuan Han Chinese patients with catheter ablation of atrial fibrillation.

Methods: A total of 222 atrial fibrillation patients taking stable warfarin therapy after catheter ablation operation were enrolled in this study. The study population included had high $(\geq 2)$ risk according to the CHA2DS2-VASc risk score. Genotypes of VKORC1 rs9923231, CYP4F2 rs2108622 and NQO1 rs1800566 were analyzed by using the polymerase chain reaction restriction fragment length polymorphism method (PCR-RFLP). Multiple linear regression analysis was applied to depict the impact of VKORC1 rs9923231, CYP4F2 rs2108622 and NQO1 rs1800566 on the daily stable warfarin dose requirement.

Results: Carriers of VKORC1 rs9923231 AG/GG genotypes required significantly higher warfarin dose $3.03 \pm 0$. $28 \mathrm{mg} /$ day, $7.19 \mathrm{mg} /$ day, respectively) than AA carriers ( $2.52 \pm 0.07 \mathrm{mg} /$ day; $P<0.001)$. Carriers of CYP4F2 rs 2108622 $\mathrm{CT} / \mathrm{TT}$ genotypes required significantly higher warfarin dose $(3.38 \pm 0.22 \mathrm{mg} /$ day, $2.79 \pm 0.19 \mathrm{mg} /$ day, respectively) than CC carriers $(2.41 \pm 0.08 \mathrm{mg} /$ day; $\mathrm{P}<0.001)$. However, the warfarin dose for carriers of NQ01 rs $1800566 \mathrm{CT} / \mathrm{TT}$ genotypes $(2.46 \pm 0.24 \mathrm{mg} /$ day, $3.01 \pm 0.27 \mathrm{mg} /$ day, respectively) was not significantly higher than that for the CC carriers $(2.33 \pm 0.1 \mathrm{mg} /$ day). The multiple linear regression model including genotypes and demographic characteristics, could explain $20.1 \%$ of individual variations in the daily stable warfarin dose in Sichuan Han Chinese. VKORC1 rs9923231 contributed most (15\%) to the individual variations in daily stable warfarin dose, while CYP4F2 rs2108622 contributed least (3\%).

Conclusion: NQO1 rs1800566 is not a significant genetic factor of warfarin dose for Han Chinese, whereas VKORC1 rs9923231 and CYP4F2 rs2108622 are significant genetic factors, which could explain 15\% and approximately 3\% of individual variations in the daily stable warfarin dose respectively.
\end{abstract}

Keywords: VKORC1, CYP4F2, NQO1, Catheter ablation, Atrial fibrillation, Warfarin

\footnotetext{
* Correspondence: cuikaijun@hotmail.com

${ }^{\dagger}$ Equal contributors

2Department of Cardiology, West China Hospital, Sichuan University,

Chengdu, People's Republic of China

Full list of author information is available at the end of the article
}

(c) The Author(s). 2018 Open Access This article is distributed under the terms of the Creative Commons Attribution 4.0 International License (http://creativecommons.org/licenses/by/4.0/), which permits unrestricted use, distribution, and reproduction in any medium, provided you give appropriate credit to the original author(s) and the source, provide a link to the Creative Commons license, and indicate if changes were made. The Creative Commons Public Domain Dedication waiver (http://creativecommons.org/publicdomain/zero/1.0/) applies to the data made available in this article, unless otherwise stated. 


\section{Background}

Atrial fibrillation (AF) is one of the most common cardiac rhythm disorders [1]. The population of AF cases aged $\geq 35$ years in China is 5.26 million according to 2010 Chinese Census and the number of AF ablation is increasing rapidly. Catheter ablation is superior to antiarrhythmic drugs in maintaining sinus rhythm [1]. The perioperative stage of atrial fibrillation catheter ablation refers to 3 weeks before operation, intraoperative period and 3 months after surgery, which requires anticoagulant therapy to cooperate with surgical treatment. Catheter ablation is a complex procedure with high risk of asymptomatic stroke during this period, hence, the management of patients should be treated with discretion. There is highly consistent evidence from observational studies that a continuous warfarin strategy during radiofrequency catheter ablation of AF reduces the risk of thromboembolic complications without increasing the risk of bleeding. Warfarin, an oral anticoagulant drug, is prescribed for patients who have undergone a catheter ablation procedure for treating atrial fibrillation. However, because of ethnic and individual dosing variations, warfarin dosage should be based on the International Normalized Ratio (INR) and carefully regulated [2]. Inadequate warfarin dosage could lead to harmful effects such as bleeding and thromboembolism, especially at the initial treatment phase [3].

Warfarin dosage has been found to be significantly associated with single nucleotide polymorphisms (SNPs) in the genes, vitamin $\mathrm{K}$ epoxide reductase complex subunit 1 (VKORC1) and cytochrome P450 complex subunit 4F2 (CYP4F2) [4-12]. However, SNPs in VKORC1 and $C Y P 4 F 2$ are reported to be significantly different due to different ethnic backgrounds [5, 11, 13-16]. The G allele of VKORC1-1639 and the C allele of VKORC1-1173, which are responsible for higher stable warfarin dose, were present in higher frequencies in Caucasian than in the Han Chinese population [14-17]. The $\mathrm{T}$ allele of CYP4F2 rs2108622, also responsible for higher stable warfarin dose [5], had a higher frequency in Indian and Caucasian population than in the Chinese and AfricanAmerican population [11].

The dicoumarol-sensitive $\mathrm{NAD}(\mathrm{P}) \mathrm{H}$ : quinone oxidoreductase 1 (NQO1) catalyzes the two-electron reduction of several quinones, including vitamin $\mathrm{K}$ (K1, K2 and K3). NQO1 is thought to reduce vitamin $\mathrm{K}$ to vitamin $\mathrm{K}$ hydroquinone that functions as a co-factor for the $\gamma$-carboxylation and further activation of clotting factors [18]. Thus, the NQO1 gene is considered to be an additional candidate genetic factor that can affect warfarin dose. However, this hypothesis is challenged by two findings. Firstly, NQO1-deficient mice dosed with warfarin are able to reduce vitamin $\mathrm{K}$ and do not manifest a bleeding problem, questioning the role of NQO1 in vitamin K reduction [19, 20]. Secondly, SNPs in the NQO1 gene exhibit ethnic variation. The $\mathrm{T}$ allele of NQO1 rs1800566, which is responsible for a higher stable warfarin dose [4], has higher frequency in HispanicAmericans than in African-Americans [4]. Besides, NQO1 is found to have a significant association with warfarin dose in Hispanic-Americans [4], but is not associated with warfarin dose in African-Americans [21]. Till date, no studies have been performed in the Sichuan Han Chinese population. Therefore, it is important to determine if NQO1 variants also influence warfarin dose in the Han Chinese patients.

Herein, we examined the impact of ethnic variation in VKORC1, CYP4F2 and NQO1 genes on warfarin dosage in the Han Chinese patients.

\section{Methods}

\section{Study subjects}

Patients enrolled in this study must meet five requirements: (1) underwent a catheter ablation procedure for atrial fibrillation; (2) received oral warfarin at a stable dose for at least 3 weeks prior to catheter ablation and 3 months after ablation; (3) their INR values controlled in a range of 1.5 to 3.0; (4) Han Chinese living in the Sichuan Province; (5) did not have a history of liver dysfunction or liver enzymes $>3$ times the upper limit of normal. A total of 222 patients (82 males and 140 females) in West China Hospital were studied. Their demographic information including age, body weight, height and stable warfarin dosage was carefully recorded, and their blood samples were collected for genotype determination. The study population included had high ( $\geq 2)$ risk according to the CHA2DS2-VASc risk score. The Ethics Committee of West China Hospital, Sichuan University approved this study. All participants provided their written informed consent to participate in this study. The ethics committees approved this consent procedure.

\section{Genotyping of polymorphisms}

Genomic DNA was isolated from blood samples using a commercially available kit (QIAamp DNA Blood Mini Kit, Qiagen, CA). SNPs, including VKORC1 rs9923231, CYP4F2 rs2108622 and NQO1 rs1800566, were determined by a polymerase chain reaction-restriction fragment length polymorphism (PCR-RFLP) method. All PCR reactions were carried out in a $25 \mu \mathrm{l}$ volume containing $50 \mathrm{ng}$ genomic DNA, $2.5 \mathrm{mM}$ dNTPs, $10 \mathrm{mM}$ each of forward and reverse primers, $2.5 \mathrm{ml}$ 10X Ex Taq buffer and 0.75 U Ex Taq DNA polymerase (Takara, Japan). PCR thermocycling consisted of an initial denaturation period of $5 \mathrm{~min}$ at $95{ }^{\circ} \mathrm{C}$; then 40 cycles of a denaturation at $95{ }^{\circ} \mathrm{C}$ for $30 \mathrm{~s}$, an annealing period of $30 \mathrm{~s}$ at $62{ }^{\circ} \mathrm{C}$ for NQO1, $58{ }^{\circ} \mathrm{C}$ for $C Y P 4 F 2,61{ }^{\circ} \mathrm{C}$ for $V K O R C 1$, an extension period for $45 \mathrm{~s}$ at $72{ }^{\circ} \mathrm{C}$; and a final extension for $10 \mathrm{~min}$ at $72{ }^{\circ} \mathrm{C}$. Details on forward/reverse primer sequences, amplified product sizes and restriction enzymes used are shown in Table 1. Genotyping results were confirmed by repeating the reactions twice. 


\section{Statistical analysis}

The frequency distributions of VKORC1 rs9923231, CYP4F2 rs2108622 and NQO1 rs1800566 were tested for deviation from Hardy-Weinberg equilibrium using the $x^{2-}$ test. The differences in warfarin dose between the groups categorized by SNPs were analyzed by a two-sample $t$-test. Variables (age, body surface area, gender and variation of SNPs) associated with warfarin dose were analyzed by Pearson's correlation coefficient and the $\mathrm{X}^{2}$-test. Variables with $P \leq 0.1$, and not strongly correlated with other factors, were analyzed by multiple linear regression analysis to find their joint association with warfarin dose. Data were analyzed using SPSS ver.17.0 (SPSS Inc., Chicago, IL). $P<0.05$ was considered to be statistically significant. Data are shown as number (percentage) or mean $\pm \mathrm{SD}$ (range).

\section{Results}

Patient demographic and clinical characteristics

A total of 222 atrial fibrillation patients taking stable warfarin therapy before catheter ablation procedure were studied, and their demographic and clinical characteristics are summarized in Table 2. Patient age ranged from 21 to 71 years, with a mean age of $47.5 \pm 0.72$ years. Body surface area of patients ranged from 1.3 to $2.35 \mathrm{~m}^{2}$, with a mean of $1.7 \pm 0.01 \mathrm{~m}^{2} .222$ patients had successfully controlled their INR values to a range of 1.5 to 3.0 with a daily stable warfarin dose $(2.05 \pm 0.05 \mathrm{mg} /$ day $)$.

\section{Genotype analysis}

Genotypes of VKORC1 rs9923231, CYP4F2 rs2108622 and NQO1 rs1800566 were successfully determined for 222, 221 and 116 patients, respectively. The genotyping results in Table 3 showed that the frequency of the mutated allele of CYP4F2 rs2108622 and NQO1 rs1800566 was low - $19.5 \%$ of all patients carried the $\mathrm{T}$ allele of CYP4F2 rs2108622 and 13\% carried the T allele of NQO1 rs1800566. In contrast, the frequency of the mutated allele of VKORC1 rs9923231 was high - 90\% patients carried the A allele of VKORC1 rs9923231, while only 1 patient carried the wild type (GG). The genotype distributions of VKORC1 rs9923231 and NQO1 rs1800566 are in HardyWeinberg equilibrium,except CYP4F2 rs2108622.
Table 2 Demographic and clinical characteristics of Sichuan Han Chinese patients with catheter ablation of atrial fibrillation

\begin{tabular}{ll}
\hline Variable & Patients $(n=222)$ \\
\hline Mean Age \pm SD(Range)(years) & $47.5 \pm 0.72(21-71)$ \\
Male & $47.1 \pm 1.23(21-71)$ \\
Female & $47.7 \pm 0.899(23-67)$ \\
Gender & \\
Male & $82(36.9 \%)$ \\
Female & $140(63.1 \%)$ \\
Mean Body Surface Area \pm SD (Range) $\left(\mathrm{m}^{2}\right)$ & $1.7 \pm 0.01(1.3-2.35)$ \\
Male & $1.84 \pm 0.02(1.53-2.35)$ \\
Female & $1.63 \pm 0.01(1.3-2.07)$ \\
Stable warfarin dose \pm SD (mg /day) & $2.05 \pm 0.05$ \\
Average INR & \\
$1.5-2.0$ & $120(54.1 \%)$ \\
$2.0-2.5$ & $83(37.4 \%)$ \\
$2.5-3.0$ & $19(8.5 \%)$
\end{tabular}

The data are shown as mean \pm SD. Range: the data range from the lowest value to the highest. \%: percentage. INR: International Normalized Ratio

\section{Impact of VKORC1 rs9923231, CYP4F2 rs2108622 and NQO1 rs1800566 SNPs on the daily stable warfarin dose} The association of the daily stable warfarin dose with VKORC1 rs9923231, CYP4F2 rs2108622 and NQO1 rs1800566 genotypes is shown in Table 3 and Fig. 1. With regard to the VKORC1 rs9923231 genotype, the AG heterozygote carriers required a significantly higher warfarin dose $(3.03 \pm 0.28 \mathrm{mg} /$ day; $P<0.001)$ than the AA carriers $(2.52 \pm 0.07 \mathrm{mg} /$ day $)$, while the single carrier of wild type GG required a much higher dose $(7.19 \mathrm{mg} /$ day) than the AG and AA carriers. In patients with CYP4F2 rs2108622 genotype, the CT and TT carriers required a significantly higher warfarin dose $(3.38 \pm 0$. $22 \mathrm{mg} /$ day, $P<0.001 ; 2.79 \pm 0.19 \mathrm{mg} /$ day, $P<0.001$, respectively) than the CC wild type carriers $(2.41 \pm 0$. $08 \mathrm{mg} /$ day). With regard to the NQO1 rs1800566 genotype, the warfarin dose for the CT and TT carriers (2.46 $\pm 0.24 \mathrm{mg} /$ day and $3.01 \pm 0.27 \mathrm{mg} /$ day, respectively) was not significantly higher than the $\mathrm{CC}$ wild type carriers $(2.33 \pm 0.1 \mathrm{mg} /$ day $)$.

Table 1 Single Nucleotide Polymorphism Genotyping based on the PCR-RFLP method

\begin{tabular}{|c|c|c|c|c|}
\hline SNP & Forward (F) and Reverse (R) Primer Sequence $\left(5^{\prime} \rightarrow 3^{\prime}\right)$ & Extended size(bp) & Restriction Enzyme & Reference \\
\hline $\begin{array}{l}\text { NQO1 } \\
\text { rs1800566 }\end{array}$ & $\begin{array}{l}\text { F: AAGCCCAGACCAACTTCT } \\
\text { R: GCGITCTCCATCCTTC }\end{array}$ & 196 & Hinf I & {$[3,16]$} \\
\hline $\begin{array}{l}\text { VKORC1 } \\
\text { rs9923231 }\end{array}$ & $\begin{array}{l}\text { F: ATCCCTCTGGGAAGTCAAGC } \\
\text { R: CACCTTCAACCTCTCCATCC }\end{array}$ & 636 & $\mathrm{Bcnl}$ & {$[4]$} \\
\hline $\begin{array}{l}\text { CYP4F2 V433 M } \\
\text { rs2108622 }\end{array}$ & $\begin{array}{l}\text { F: AGTCCCGGTCATCTCCCGCCAT } \\
\text { R: CGCCAGCCTTGGAGAGACAGACA }\end{array}$ & 358 & Pvull & {$[4]$} \\
\hline
\end{tabular}


Table 3 The allelic frequencies and genotype distributions in Sichuan Han Chinese patients with catheter ablation of atrial fibrillation

\begin{tabular}{|c|c|c|c|c|c|c|}
\hline Gene & SNP & Genotype & Patient Number (\%) & Mean stable warfarin dose \pm SD (mg/day) & Allele & Frequency Number (\%) \\
\hline \multirow[t]{3}{*}{ NQO1 } & \multirow[t]{3}{*}{ rs1800566 } & CC & $90(78)$ & $2.33 \pm 0.1$ & C & $202(87)$ \\
\hline & & $C T$ & $22(19)$ & $2.46 \pm 0.24$ & T & $30(13)$ \\
\hline & & $\pi$ & $4(3)$ & $3.01 \pm 0.27$ & & \\
\hline \multirow[t]{3}{*}{ VKORC1 } & \multirow[t]{3}{*}{ rs9923231 } & GG & $1(0.4)$ & 7.19 & G & $45(10)$ \\
\hline & & $A G$ & $43(19)$ & $3.03 \pm 0.28$ & A & 399(90) \\
\hline & & AA & $178(80)$ & $2.52 \pm 0.07$ & & \\
\hline \multirow[t]{3}{*}{ CYP4F2 V433 M } & \multirow[t]{3}{*}{ rs2108622 } & $\mathrm{CC}$ & $155(70)$ & $2.41 \pm 0.08$ & C & $356(80.5)$ \\
\hline & & $C T$ & $46(20)$ & $3.38 \pm 0.22$ & T & $86(19.5)$ \\
\hline & & $\Pi T$ & 20(9) & $2.79 \pm 0.19$ & & \\
\hline
\end{tabular}

SNP single nucleotide polymorphism

\section{Contribution of demographic characteristics and} genotype variation to the daily stable warfarin dose

Multiple linear regression analysis was used to investigate the contribution of demographic characteristics and genotype variation to the daily stable warfarin dose in Sichuan Han Chinese population. Our data indicate that several factors (VKORC1 rs9923231, CYP4F2 rs2108622, NQO1 rs1800566, age, weight, height and gender) contributed to $20.1 \%$ of individual variations in the daily stable warfarin dose (Table 4). VKORC1 rs9923231 exhibited a significant correlation with the daily stable warfarin dose $(P<0.001)$ and contributed the most $(15 \%)$ to individual variations in the daily stable warfarin dose. CYP4F2 rs2108622 also contributed approximately $3 \%$ to variation in the daily stable warfarin dose $(P<0$. 001). However, NQO1 rs1800566 was not significantly associated with the daily stable warfarin dose $(P=0.12)$.

\section{Discussion}

In this study, the effect of VKORC1 rs9923231, CYP4F2 rs2108622 and NQO1 rs1800566 genotypes on the daily stable warfarin dose in Sichuan Han Chinese patients with catheter ablation of atrial fibrillation was determined, and the allelic frequency and genetic distribution of these genotypes were also compared with other ethnic populations. To our knowledge, this is the first study that investigates the effect of the NQO1 rs1800566 genotype on warfarin dose in Han Chinese patients. Till date, such studies have been performed in African-American and Hispanic-American patients [4, 21], but not in Han Chinese patients. Given the ethnic variation of NQO1, there was a critical need for assessing its impact on the daily stable warfarin dose in Han Chinese patients in this study.

The alleles identified to be responsible for higher warfarin dose requirement, VKORC1 rs9923231, CYP4F2 rs2108622

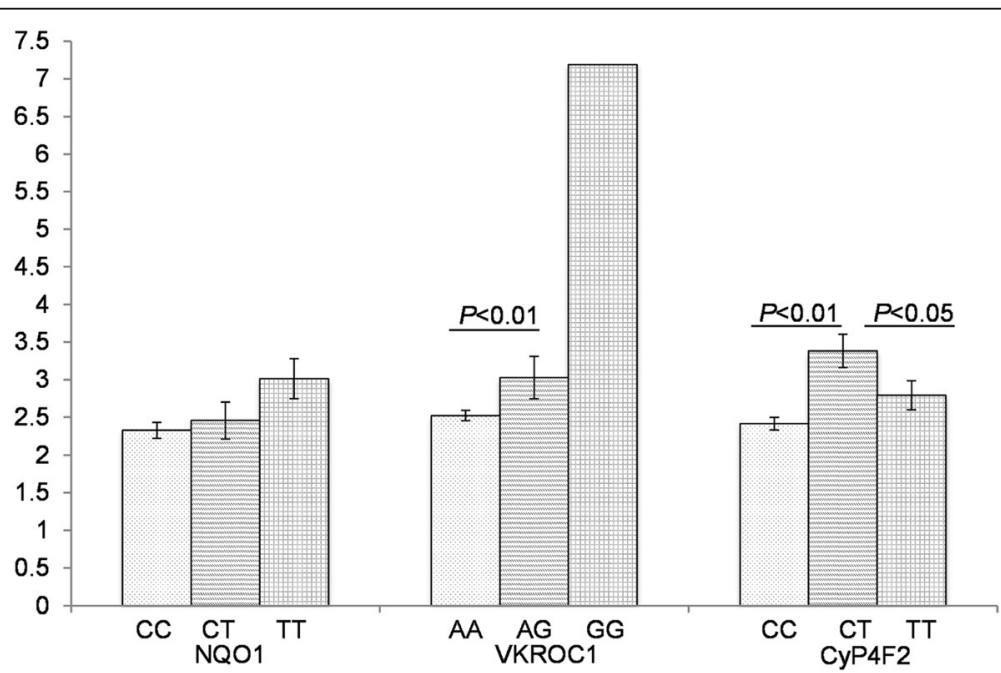

Fig. 1 Mean stable warfarin dose \pm SD (mg/day) by VKORC1 rs9923231, CYP4F2 rs2108622 and NQ01 rs1800566 genotypes. The data of Mean stable warfarin dose \pm SD are from Table 3 . The differences in warfarin dose between the groups categorized by SNPs were analyzed by a two-sample $t$-test. $P<0.05$ was considered to be statistically significant 
Table 4 Demographic and genetic factors associated with daily stable warfarin dose by multiple linear regression

\begin{tabular}{lll}
\hline Factors & Standardized coefficient & $P$-value \\
\hline Age & -0.077 & $<0.001$ \\
Gender & -0.14 & $<0.001$ \\
Body Surface Area & -0.05 & $<0.001$ \\
SNP of VKORC1 & 0.150047 & $<0.001$ \\
SNP of CYP4F2 & -0.0299 & $<0.001$ \\
SNP of NQO1 & 0.087033 & 0.12
\end{tabular}

Variables (age, body surface area, gender and variation of SNPs) associated with warfarin dose were analyzed by Pearson's correlation coefficient and the $x 2$-test. Variables with $P \leq 0.1$, and not strongly correlated with other factors, were analyzed by multiple linear regression analysis to find their joint association with warfarin dose. $P<0.05$ was considered to be statistically significant

and NQO1 rs1800566, were present at a low frequency in Sichuan Han Chinese patients, which might explain their sensitivity to warfarin and their requirement for a lower warfarin dose as compared to Caucasians. The allelic frequencies and genetic distributions of VKORC1 rs9923231 in Han Chinese patients were different from Caucasian patients, the $\mathrm{G}$ allele of VKORC1 rs9923231 had lower frequency in Han Chinese patients than in Caucasian patients. This finding might provide a reason to the different warfarin dose requirement between these two populations $[14,16]$. This finding also suggests that $V K O R C 1$ is the genetic factor for ethnic variations in warfarin dose. However, the allelic frequencies and genetic distributions of the CYP4F2 rs2108622 in Han Chinese patients were not different from Caucasian patients, confirming a previous study that suggested that CYP4F2 did not influence ethnic variations in warfarin dose [5]. The allelic frequency and genetic distribution of NQO1 rs1800566 in Han Chinese patients were not different from the African-American population either [21], suggesting that NQO1 is also not a genetic factor in modulating ethnic variation in warfarin dose.

Multiple linear regression analysis demonstrated that VKORC1 rs9923231 and CYP4F2 rs2108622 associated significantly with the daily stable warfarin dose $(P<0.001)$ and contributed 15 and $3 \%$ to individual variation in the daily stable warfarin dose, respectively. These results suggests that VKORC1 rs9923231 and CYP4F2 rs2108622 are significant genetic factors contributing to individual differences in warfarin dose within an ethnic population, as also indicated in previous studies [5, 8, 10, 11, 13, 22, 23]. Therefore, monitoring of these two genotypes could help determine the personalized warfarin dose requirement in Han Chinese patients. Consistent with a previous study in African-American patients [21], NQO1 rs1800566 is not significantly associated with the daily stable warfarin dose in Han Chinese patients as well, suggesting that NQO1 does not contribute to individual variations in warfarin dose within an ethnic population. Together with an in vitro study demonstrating that $V K O R C 1$ plays a major role in vitamin $\mathrm{K}$ cycle whereas other enzymes play smaller roles [24], our study suggests that NQO1 may not be a significant genetic factor influencing warfarin dose.

While our data are limited by our small sample size, the sample we collected were almost Han Chinese and the other nationalities will be researched in the future.

\section{Conclusion}

Our current data support VKORC1 and CYP4F2, but not NQO1, genotypes in prediction of warfarin dose requirements in Han Chinese. Moving forward, developing the predictive ability that take genetic characteristics into account may help improve dose prescribing and reduce the risk of bleeding and thrombosis during the warfarin initiation period. Formal algorithm establishment will require a large sample.

\section{Abbreviations}

AF: atrial fibrillation; bp: base pair; INR: International Normalized Ratio; PCRRFLP: polymerase chain reaction restriction fragment length polymorphism; SNP: single nucleotide polymorphisms

\section{Acknowledgements}

The authors appreciate the cooperation of patients in the current study and express sincere thanks to the Chengdu Regencell Biotechnology Co., Ltd. who provided technical support.

\section{Funding}

This research received no specific grant from any funding agency in the public, commercial, or not-for-profit sectors.

\section{Availability of data and materials}

The datasets generated and/or analyzed during the current study are available from the corresponding author on reasonable request.

\section{Authors' contributions}

Conceived and designed the experiments: KY and KJC. Performed the experiments: KY, JL, ZHX and YHC. Analyzed the data: $J$ L and WLY. Contributed to reagents/materials/analysis tools: KY, JL, YHC, ZHX, WLY and KJC. Wrote the paper: $J L$ and $W L Y$. All authors read and approved the final manuscript.

\section{Ethics approval and consent to participate}

All participants read the purpose statement of the investigation and signed the informed consent. This study has been approved by the Research Ethics Committee in West China Clinical Medicine School and have therefore been performed in accordance with the ethical standards laid down in the 1964 Declaration of Helsinki and its later amendments.

\section{Consent for publication}

Consent for publication was obtained in all participants.

\section{Competing interests}

The authors declare that they have no competing interests.

\section{Publisher's Note}

Springer Nature remains neutral with regard to jurisdictional claims in published maps and institutional affiliations.

\section{Author details}

${ }^{1}$ College of Life Science, Sichuan Normal University, Chengdu, People's Republic of China. ${ }^{2}$ Department of Cardiology, West China Hospital, Sichuan University, Chengdu, People's Republic of China. ${ }^{3}$ State Key Laboratory of Biotherapy/Collaborative Innovation Center for Biotherapy, West China Hospital, Sichuan University, Chengdu, People's Republic of China. ${ }^{4}$ Department of Cardiac Surgery, West China Hospital of Sichuan University, Chengdu, China. 
Received: 10 September 2017 Accepted: 9 May 2018

Published online: 18 May 2018

\section{References}

1. Anselmino M, Ferraris F, Cerrato N, Barbero U, Scaglione M, Gaita F. Left persistent superior vena cava and paroxysmal atrial fibrillation: the role of selective radio-frequency transcatheter ablation. J Cardiovasc Med (Hagerstown). 2014;15(8):647-52.

2. van Walraven C., Jennings A., Oake N., Fergusson D., and Forster A.J., Effect of study setting on anticoagulation control: a systematic review and metaregression. Chest, 2006. 129(5): p. 1155-1166.

3. Wysowski DK, Nourjah P, Swartz L. Bleeding complications with warfarin use: a prevalent adverse effect resulting in regulatory action. Arch Intern Med. 2007;167(13):1414-9.

4. Bress A, Patel SR, Perera MA, Campbell RT, Kittles RA, Cavallari LH. Effect of NQO1 and CYP4F2 genotypes on warfarin dose requirements in HispanicAmericans and African-Americans. Pharmacogenomics. 2012;13(16):1925-35.

5. Cen HJ, Zeng WT, Leng XY, Huang M, Chen X, Li JL, Huang ZY, Bi HC, Wang XD, He YL, He F, Zhou RN, Zheng QS, Zhao LZ. CYP4F2 rs2108622: a minor significant genetic factor of warfarin dose in Han Chinese patients with mechanical heart valve replacement. Br J Clin Pharmacol. 2010;70(2):234-40.

6. Hammed A, Matagrin B, Spohn G, Prouillac C, Benoit E, Lattard V. VKORC1L1, an enzyme rescuing the vitamin $\mathrm{K}$ 2,3-epoxide reductase activity in some extrahepatic tissues during anticoagulation therapy. J Biol Chem. 2013; 288(40):28733-42.

7. Huang SW, Xiang DK, Wu HL, Chen BL, An BQ, Li GF. Impact of five genetic polymorphisms on inter-individual variation in warfarin maintenance dose. Zhonghua Yi Xue Yi Chuan Xue Za Zhi. 2011;28(6):661-5.

8. Krishna Kumar D, Shewade DG, Loriot MA, Beaune P, Balachander J, Sai Chandran BV, Adithan C. Effect of CYP2C9, VKORC1, CYP4F2 and GGCX genetic variants on warfarin maintenance dose and explicating a new pharmacogenetic algorithm in south Indian population. Eur J Clin Pharmacol. 2014;70(1):47-56.

9. Liang R, Wang C, Zhao H, Huang J, Hu D, Sun Y. Influence of CYP4F2 genotype on warfarin dose requirement-a systematic review and metaanalysis. Thromb Res. 2012;130(1):38-44.

10. Perini JA, Struchiner CJ, Silva-Assuncao E, Suarez-Kurtz G. Impact of CYP4F2 rs2108622 on the stable warfarin dose in an admixed patient cohort. Clin Pharmacol Ther. 2010;87(4):417-20.

11. Singh O, Sandanaraj E, Subramanian K, Lee LH, Chowbay B. Influence of CYP4F2 rs2108622 (V433M) on warfarin dose requirement in Asian patients. Drug Metab Pharmacokinet. 2011;26(2):130-6.

12. Wadelius M, Chen LY, Downes K, Ghori J, Hunt S, Eriksson N, Wallerman O, Melhus H, Wadelius C, Bentley D, Deloukas P. Common VKORC1 and GGCX polymorphisms associated with warfarin dose. Pharmacogenomics J. 2005; 5(4):262-70.

13. Liang R, Li L, Li C, Gao Y, Liu W, Hu D, Sun Y. Impact of CYP2C9*3, VKORC11639, CYP4F2rs2108622 genetic polymorphism and clinical factors on warfarin maintenance dose in Han-Chinese patients. J Thromb Thrombolysis. 2012;34(1):120-5.

14. Larramendy-Gozalo C., Yang J.Q., Verstuyft C., Bodin L., Dubert L., Zhang Y., Xu C., Fan L., Jaillon P., and Becquemont L., Genetic polymorphism of vitamin K epoxide reductase (VKORC1) 1173C $>$ T in a Chinese and a Caucasian population. Basic Clin Pharmacol Toxicol, 2006. 98(6): p. 611-613.

15. Yang J, Huang C, Shen Z, Miao L. Contribution of $1173 \mathrm{C}>\mathrm{T}$ polymorphism in the VKORC1 gene to warfarin dose requirements in Han Chinese patients receiving anticoagulation. Int J Clin Pharmacol Ther. 2011;49(1):23-9.

16. Yuan HY, Chen JJ, Lee MT, Wung JC, Chen YF, Charng MJ, Lu MJ, Hung CR, Wei $\mathrm{CY}$, Chen $\mathrm{CH}$, Wu JY, Chen YT. A novel functional VKORC1 promoter polymorphism is associated with inter-individual and inter-ethnic differences in warfarin sensitivity. Hum Mol Genet. 2005;14(13):1745-51.

17. Yan X, Yang F, Zhou H, Zhang H, Liu J, Ma K, Li Y, Zhu J, Ding J. Effects of VKORC1 genetic polymorphisms on warfarin maintenance dose requirement in a Chinese Han population. Med Sci Monit. 2015;21:3577-84.

18. Wallin $\mathrm{R}$, Gebhardt $\mathrm{O}$, Prydz H. NAD(P)H dehydrogenase and its role in the vitamin K (2-methyl-3-phytyl-1,4-naphthaquinone)-dependent carboxylation reaction. Biochem J. 1978;169(1):95-101.

19. Ingram BO, Turbyfill JL, Bledsoe PJ, Jaiswal AK, Stafford DW. Assessment of the contribution of $\mathrm{NAD}(\mathrm{P}) \mathrm{H}$-dependent quinone oxidoreductase 1 (NQO1) to the reduction of vitamin $\mathrm{K}$ in wild-type and NQO1-deficient mice. Biochem J. 2013;456(1):47-54.
20. Radjendirane V, Joseph P, Lee YH, Kimura S, Klein-Szanto AJ, Gonzalez FJ, Jaiswal AK. Disruption of the DT diaphorase (NQO1) gene in mice leads to increased menadione toxicity. J Biol Chem. 1998;273(13):7382-9.

21. Momary KM, Shapiro NL, Viana MA, Nutescu EA, Helgason CM, Cavallari LH. Factors influencing warfarin dose requirements in African-Americans. Pharmacogenomics. 2007;8(11):1535-44.

22. Jorgensen AL, FitzGerald RJ, Oyee J, Pirmohamed M, Williamson PR. Influence of CYP2C9 and VKORC1 on patient response to warfarin: a systematic review and meta-analysis. PLoS One. 2012;7(8):e44064.

23. Sconce EA, Khan TI, Wynne HA, Avery P, Monkhouse L, King BP, Wood P, Kesteven P, Daly AK, Kamali F. The impact of CYP2C9 and VKORC1 genetic polymorphism and patient characteristics upon warfarin dose requirements: proposal for a new dosing regimen. Blood. 2005;106(7):2329-33.

24. Tie JK, Jin DY, Straight DL, Stafford DW. Functional study of the vitamin K cycle in mammalian cells. Blood. 2011;117(10):2967-74.

\section{Ready to submit your research? Choose BMC and benefit from:}

- fast, convenient online submission

- thorough peer review by experienced researchers in your field

- rapid publication on acceptance

- support for research data, including large and complex data types

- gold Open Access which fosters wider collaboration and increased citations

- maximum visibility for your research: over $100 \mathrm{M}$ website views per year

At BMC, research is always in progress.

Learn more biomedcentral.com/submissions 